18. TABLES of $\operatorname{TAN}^{-1}(m / n)(Q 14$, p. 431).-I have a 9-place manuscript table of $\tan ^{-1}(m / n)$, where $m$ and $n$ are integers ranging from 1 to 26 inclusive. However, there may be errors, as the table has not been checked by use. Photostat copies of this manuscript are permitted. Mr. Pollack may also be interested in my paper, "A table of inverse trigonometric functions in radians," Terrestrial Magnetism, v. 40, 1935, which contains (p. 311-312) a table of $\tan ^{-1} x, x=[0(.01) 1 ; 11 D]$, and which also gives the first four coefficients of a power series to be used in interpolating; by reducing to decimals the ratio in which he is interested, an ordinary ten-bank computing machine will furnish results to eleven decimals, with some uncertainty in the last figure.

Custom House,

IRWIN ROMAN

Baltimore, Md.

Editorial Note: The smaller interval of argument in the NYMTP, Table of Arc Tan $x$, Washington, $1942, x=[0(.001) 1 ; 12 \mathrm{D}]$, may be even more useful for interpolating than the Roman table. There are also tables, of doubtful accuracy, $x=[0(.00001) .001$; $.001(.0001) .0999 ; 20 \mathrm{D} ; 10 \mathrm{D}]$ in K. HAYASHI, Sieben- und mehrstellige Tafeln der Kreisund Hyperbelfunktionen . . ., Berlin, 1926.

\title{
CORRIGENDA ET ADDENDA
}

P. 26, 1. 1-2, for trigonometry by H. Gellibrand, Gouda, 1633., read Gouda, 1633; see RMT 79.

P. 232, 234(3), 277, 291, 299, 329, for Haurvitz, read Haurwitz.

P. 2352, 289, for Franz, read FRäNZ.

P. 252, 1. 24-25, for We shall not use the notation $\operatorname{ster}_{n} x+i \operatorname{stei}_{n} x=H_{n}\left(x i^{3 / 2}\right)$, offered by MCLACHLAN \& MEYers., read The notation $\operatorname{ster}_{n} x+i$ stei $_{n} x=H_{n}\left(x i^{3 / 2}\right)$ was employed by McLachlan \& Meyers.

P. 253, 1. 15-18, read Polar forms of the functions have been used by some writers, thus the notation of McLAchlan 2, $M_{n} e^{i \theta_{n}(x)}$, used above, is a slight modification of the notation employed by Kennelly, Laws \& Pierce 1. These writers actually use $\rho$ for this particular modulus of a complex quantity but propose the use of the notation $M$ for the modulus in general. The corresponding notation $N_{n} e^{i \phi_{n}(x)}$ of McLachlan 2, is adopted by McLachlan \& Meyers.

P. $273,1.13$, for $23 c$, read $23 c / 15$.

P. 2932, for J. G. JAEGER, read J. C. JAEGER.

P. 461, RMT, read 93 (Lowan, Salzer \& Hillman, Bickley \& Miller) 53.

P. 462, MTE 3, read (Cunningham, Euler) 26; and 58, read (Lommel, Watson) 366.

P. 478, add Thomas, L. H. 453. 